\title{
РЕГУЛИРОВАНИЕ ПОТРЕБИТЕЛЬСКОГО МИКРОФИНАНСИРОВАНИЯ В РОССИИ И ОПЫТ РАЗВИВАЮЩИХСЯ СТРАН
}

\section{REGULATION OF CONSUMER \\ MICROFINANCE \\ IN RUSSIA AND THE EXPERIENCE OF DEVELOPING COUNTRIES}

\section{Vysokov}

Summary. The article considers the issue of improving the regulation of microfinance and bank lending in Russia in order to reduce the cost of borrowed funds for consumers of financial services in the retail segment. The article analyzes the world experience in the development of microfinance in the regional context. The study found that the original social concept of microfinance is now largely replaced in the world by the commercial model, and the boundaries between microfinance and banking are blurred. At the same time, artificial barriers to competition between microfinance organizations and banks remain in Russia, which leads to an increase in the cost of loans and contributes to the development of unfair lending practices.

Keywords: microfinance, credit organizations, consumer lending.

\section{Введение}

$\mathbf{M}$ икрофинансирование возникло в 70-х годах XX века как инструмент борьбы с бедностью и изначально заключалось в предоставлении небольших сумм денежных средств лицам, лишённых доступа к банковским услугам. Первая микрофинансовая организация, Гремин Банк, созданный Мухаммадом Юнусм в 1976 году в Бангладеш выдавал займы деревенским общинам в сельской местности, преимущественно женщинам, с целью развития деревень и улучшения их экономического положения через создание микропредприятий. По мере развития микрофинансирования произошел отход от данных основополагающих принципов - социальной составляющей и направленности на поддержку наиболее бедных слоев населения, а также коммунальной основы - т.н. «смена миссии» [5, с. 13] микрофинансирования и его коммерциализация [6, с. 125], что ведет к стиранию границ между потребительским микрофинансированием и розничной банковской деятельностью. В России наблюдается аналогичная ситуация, однако действующий механизм предельных значений полной стоимости кредита/займа (далее - ПСК), ежеквартально устанавливаемых Банком России на основе средних значений

\author{
Высоков Денис Александрович \\ Аспирант, Финансовый университет при \\ Правительстве Российской Федерации, Москва \\ denisvysokov@mail.ru
}

Аннотачия. В статье рассмотрен вопрос совершенствования регулирования микрофинансирования и банковского кредитования в России с целью снижения стоимости заемных средств для потребителей финансовых услуг в розничном сегменте. Анализируется мировой опыт развития микрофинансирования в региональном разрезе. В ходе исследования было установлено, что первоначальная социальная концепция микрофинансирования в настоящее время во многом замещена в мире коммерческой моделью, а границы между микрофинансированием и банковской деятельностью являются размытыми. При этом в России сохраняются искусственные барьеры для конкуренции между микрофинансовыми организациями и банками, что ведет к удорожанию стоимости займов и способствует развитию недобросовестных практик кредитования.

Ключевые слова: микрофинансирование, кредитные организации, потребительское кредитование.

процентных ставок для каждой категории кредитов/ займов, создает искусственные барьеры для конкуренции кредитных и микрофинансовых организаций.

\section{^итературный обзор}

Весомый вклад в развитие теоретических основ микрофинансирования в России, а также формирования его методологической базы, внесли такие авторы, как: Мамута М.В., С.В. Криворучко, М.А. Абрамова, О.С. Тенетник, И.Е. Шакер, и др.

Среди зарубежных авторов, работы которых посвящены вопросам совершенствования кредитной системы, практике микрофинансирования и обоснованию его роли в мировом масштабе, следует выделить работы таких авторов, как: Yunus M., Hulme D., Mosley, P, Ghatak M., Guinnane, T. Armendariz B., Morduch J., Mossman, M., Conning, J, Bateman M., Chang H. и др.

Вместе с тем, в большинстве отечественных научных посвященных исследованию микрофинансирования в России, преобладает теоретический подход, что обуславливает необходимость дополнительных исследований в данном направлении. 


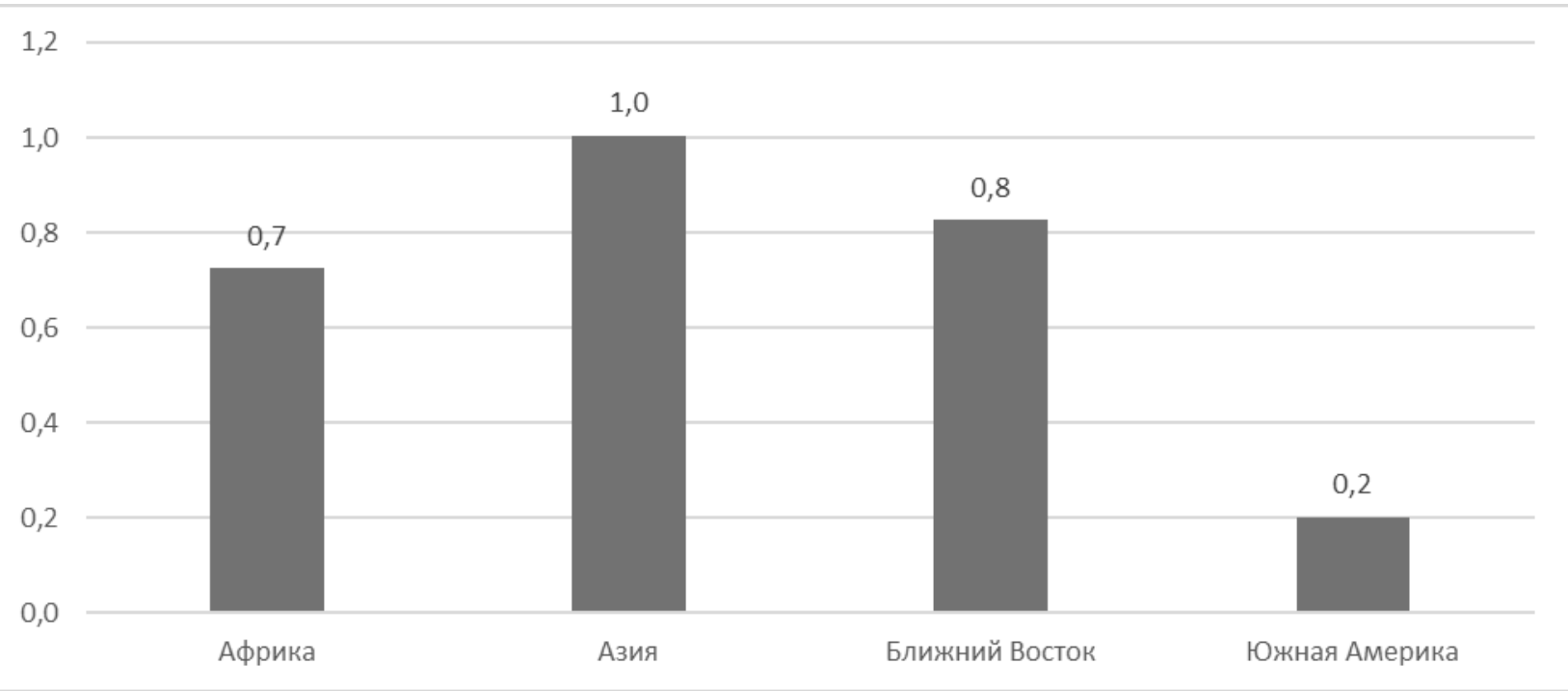

Рис. 1. Количество филиалов МФО на миллион долл. выданных микрозаймов (составлено автором по источнику [10])

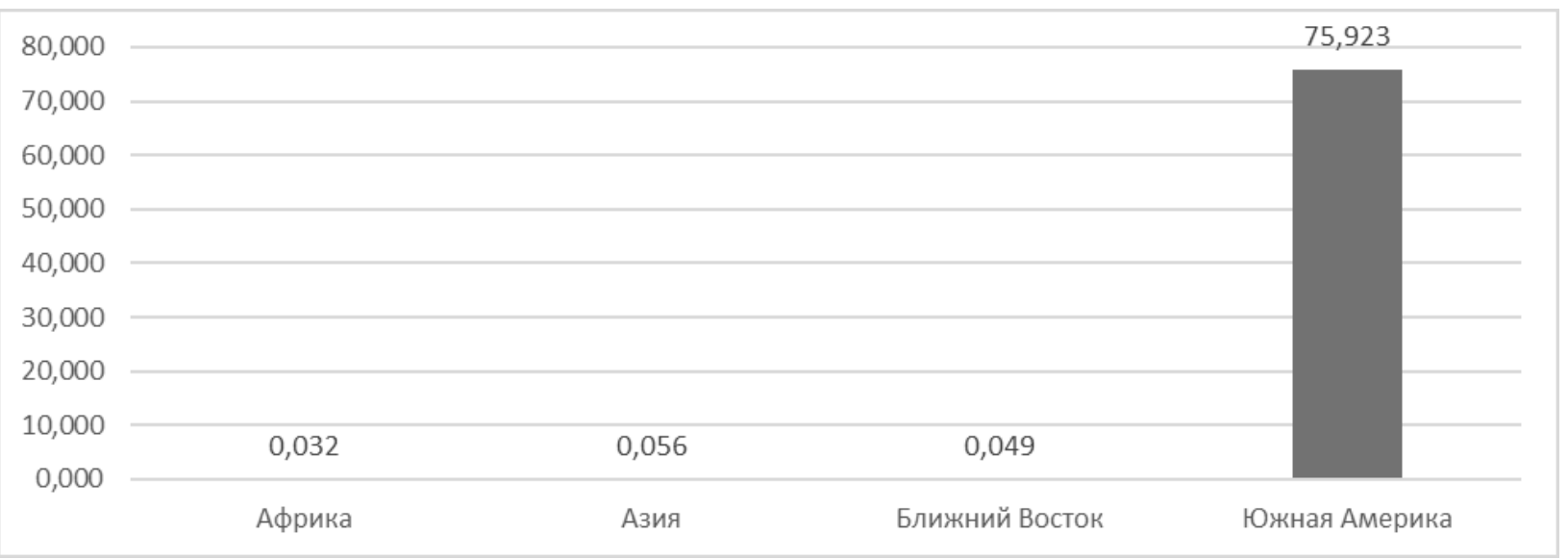

Рис. 2. Количество дополнительных офисов МФО на миллион долл. выданных микрозаймов (составлено автором по источнику [10])

\section{Анализ развития}

микрофинансирования в мире:

региональный разрез

Микрофинансирование в мире неоднородно и характеризуется региональными особенностями, однако единым является тренд на отход от социальных целей деятельности, что характеризуется коммерциализацией микрофинансовой деятельности микрофинансовых организаций (далее - МФО), изначально создававшихся как некоммерческие организации НКО, вовлечением банков в микрофинансовую деятельность [7, с. 7-8], а также укрупнением МФО и их превращением в банки $[8$, с. 5]. Как видно на рисунках 1 и 2, данный процесс наиболее выражен в Южной Америке: в данном регионе микрофинансовые услуги оказываются через обширные сети малых дополнительных отделений, что схоже с деятельностью розничных банков. При этом в иных регионах микрофинансовые услуги предоставляются в незначительном числе филиалов, а МФО практически не открывают дополнительные отделения.

Помимо этого, в Южной Америке имеется набольшее число устройств приема и выдачи денег в собственности МФО, что свидетельствует о высокой степени формализации и организованности их деятельности. (Рис. 3). 


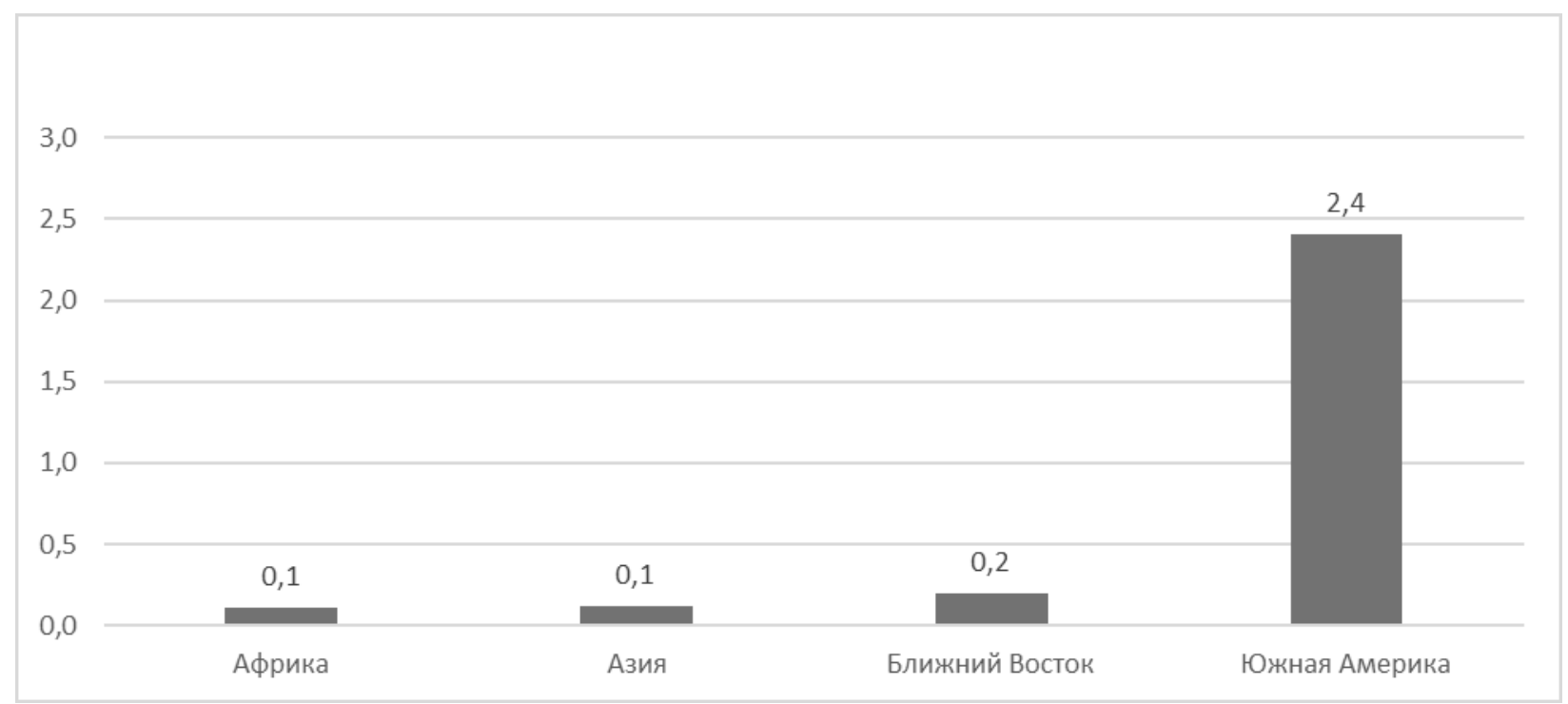

Рис. 3. Количество банкоматов МФО на миллион долл. США выданных микрозаймов (составлено автором по источнику [10])

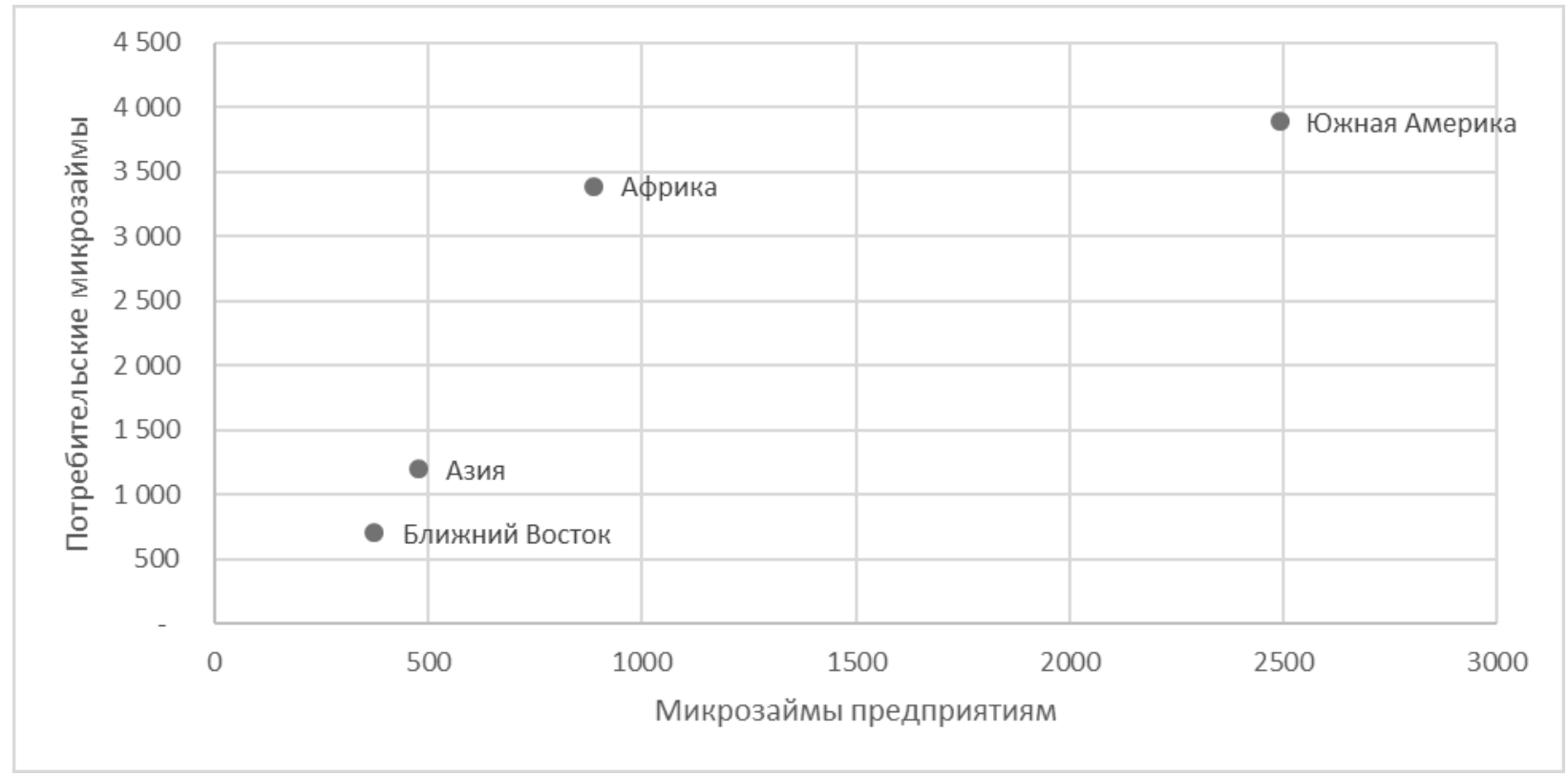

Рис. 4. Средний размер микрозайма, долл. США (составлено автором по источнику [10])

Размеры микрозаймов в Южной Америке с большим отрывом опережают иные регионы, что противоречит концепции малого размера микрозайма и также указывает на сдвиг микрофинансирования в сторону банковской деятельности, при этом не только в сфере розничного кредитования (Рис. 4).

Несмотря на то, что социальная сущность микрофинансирования при этом теряется, увеличение среднего размера займов свидетельствует о том, что процесс сближения МФО и банков, как и коммерциализации микрофинансирования, способствует повышению объемов заемных ресурсов, доступных клиентам МФО, и является естественным следствием развития микрофинансовой деятельности. Вместе с тем теряется еще одна присущая микрофинансированию черта - воспроизводственная направленность. На рисунке 5 видно, что доля микрозаймов, выданных в Латинской Америке предприятиям, ниже, чем в Азии или на ближнем востоке, при этом финансируется уже существующие 


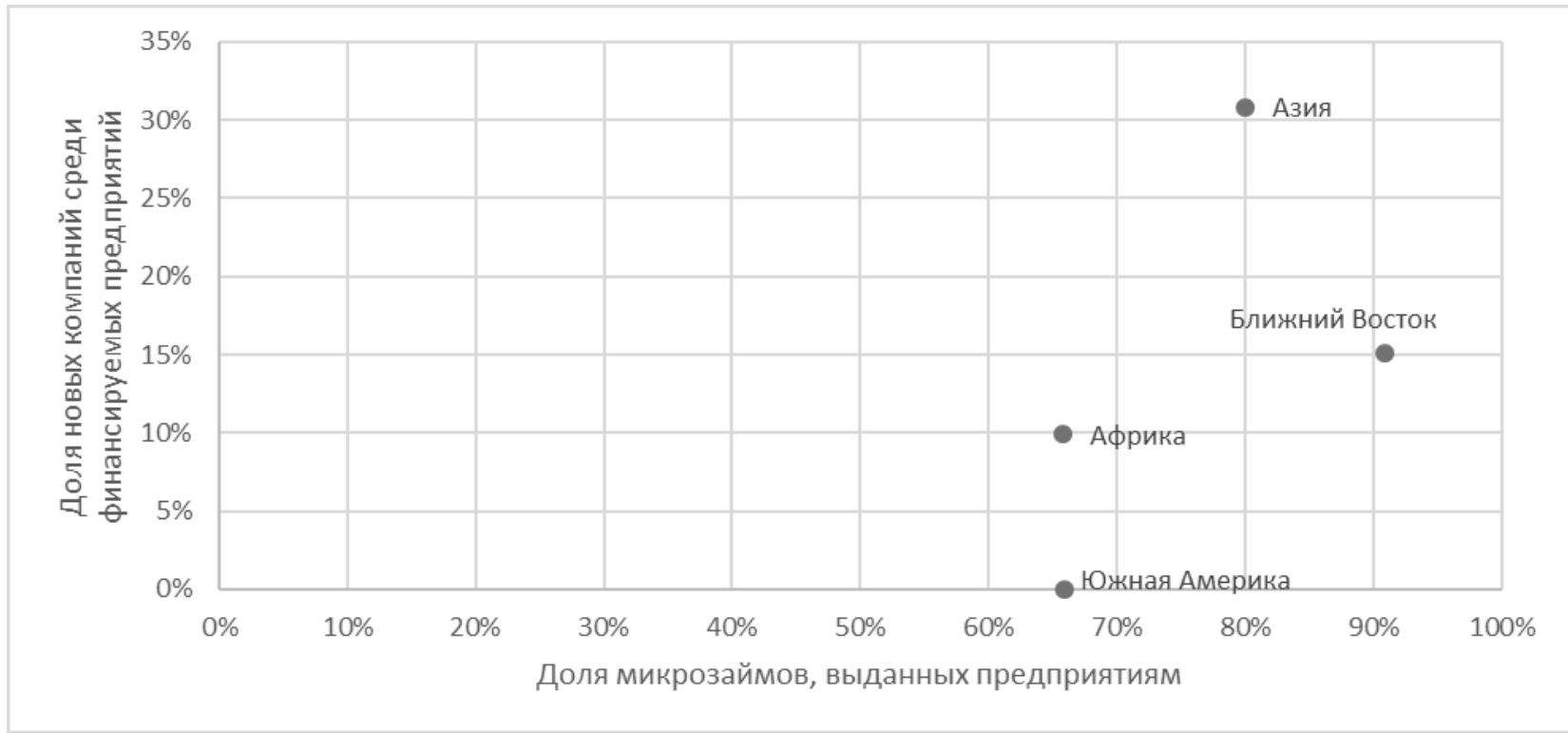

Рис. 5. Доля микрозаймов, выданных предприятиям, и доля новых компаний среди финансируемых предприятий (составлено автором по источнику [10])

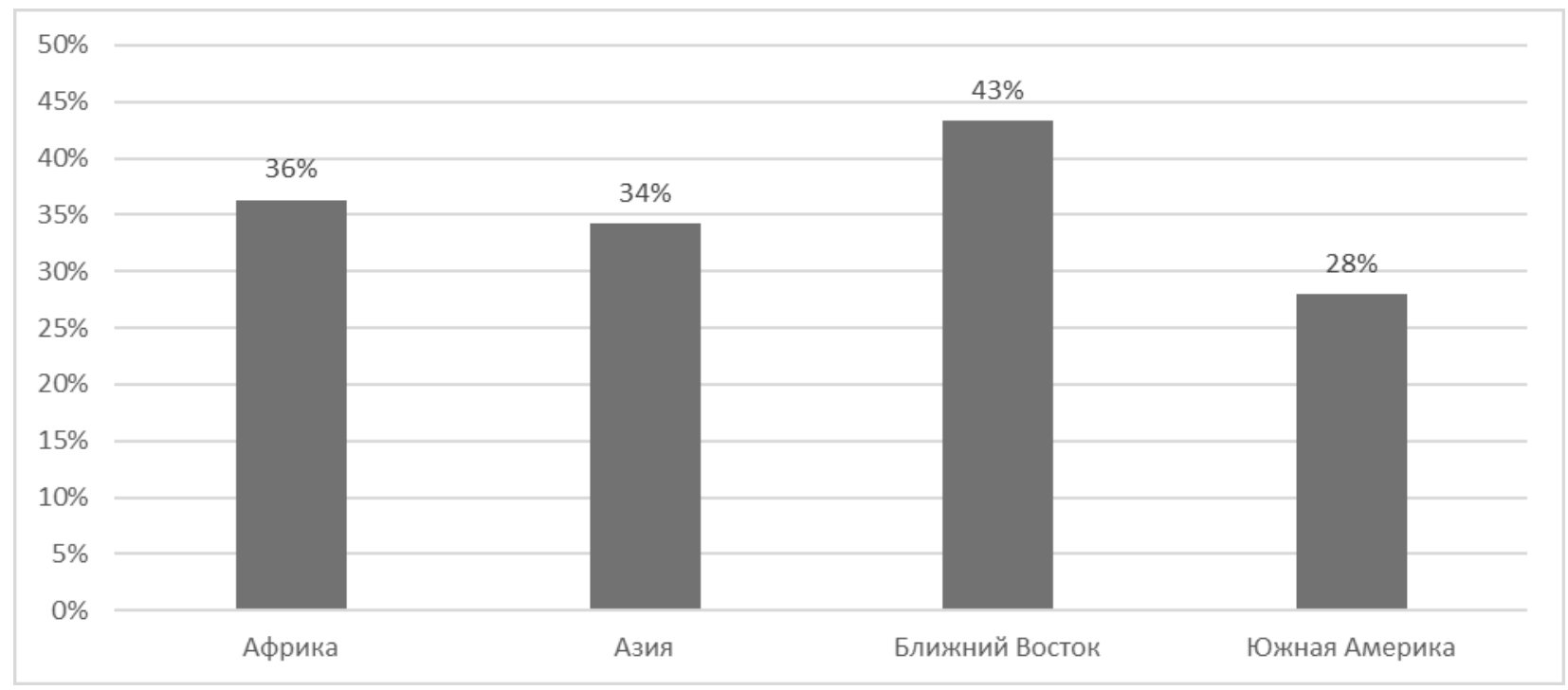

Рис. 6. Доля заемщиков МФО ниже уровня бедности (составлено автором по источнику [10])

предприятия, а не более рискованные - еще одна черта, сближающая микрофинансовую и банковскую деятельность в Южной Америке.

Высокая доля воспроизводственного микрофинансирования сохраняется на родине микрофинансирования, в Азии, а также на ближнем Востоке (в связи с религиозными запретами на потребительское кредитование). По данным показателям Африка занимает промежуточное положение между Азией и Южной Америке.
Меньший интерес латиноамериканские МФО проявляют и к слоям населения, которые исключены из банковской системы - как видно на рисунке 6, в Южной Америке наблюдается наименьшая доля бедных среди клиентов МФО.

Здесь также проявляется отход от концепции предоставления работ тем субъектам экономической деятельности, которые исключены из финансовой системы, включая по причине высокого риска невозврата займов. При этом высокий уровень бедности клиентов, 


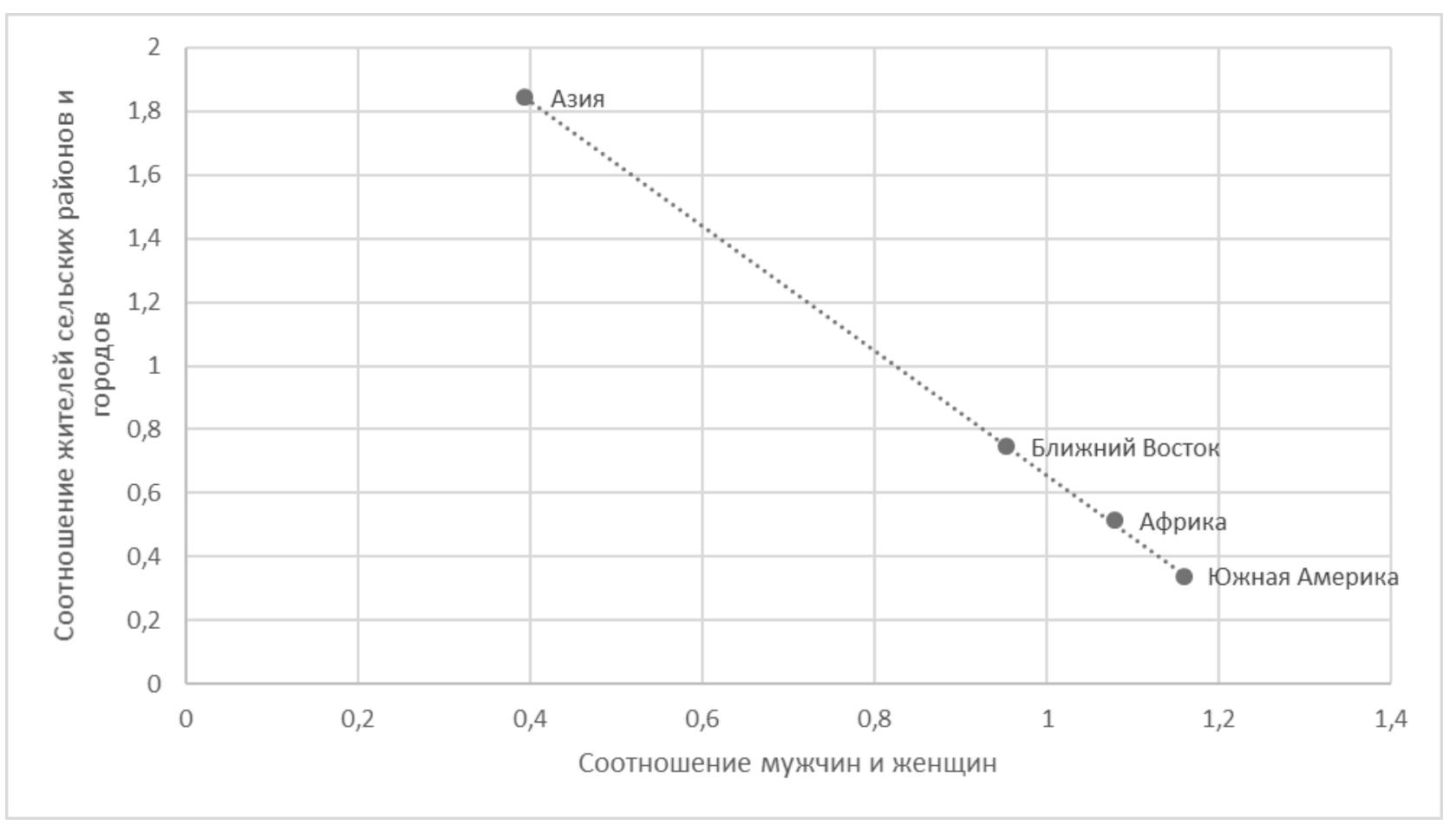

Рис. 7. Соотношение мужчин и женщин и соотношение жителей сельских районов и городов среди клиентов МФО (составлено автором по источнику [10])

как наблюдается в Африке, совместно с низким уровнем развития финансовой инфраструктуры (в Африке свыше 90\% клиентов МФО обслуживаются через агентские сети, выступающие посредниками при переводе денежных средств, что значительно превышает показатели иных регионов [9]), на текущем этапе сдерживает процесс сближения МФО и банков и их переориентации на более платежеспособных клиентов.

Аналогичные тенденции наблюдаются и в отношении половой и территориальной структуры заемщиков (Рис. 7).

МФО по мере расширения и укрупнения предпочитают выдавать микрозаймы более обеспеченным и платежеспособным слоям населения - городским жителям и мужчинам. При этом общим для всех рассматриваемых регионов является то, что доли сельских жителей и женщин среди заемщиков взаимосвязаны и отражают переход МФО в более массовый сегмент рынка кредитования. Это свидетельствует о закономерности данного процесса. В целом, такая трансформация микрофинансирования из социально-направленного в деятельность, по своей сути приближенную к банкам, связано как с увеличением финансовой доступности, так и со совершенствованием каналов обслуживания, что позволяет банкам предоставлять микрофинансовые услуги, а МФО побуждает расширят свою деятель- ность в поиске более выгодных клиентских сегментов. При этом естественной границей между микрофинансированием и банками становится уровень риска заемщиков, о чем свидетельствует относительно большая доля заемщиков МФО за чертой бедности, наблюдаемая во всех рассмотренных регионах.

\section{Микрофинансирование \\ и банковское креАитование в России: конкурентные барьеры}

В России разделение микрозаймов и банковских кредитов основано на раздельных предельных значениях ПСК, которые не могут превышать рассчитанные Банком России средние значения более, чем на треть [1]. С одной стороны, это позволяет защищать заемщиков от чрезмерно высоких процентных ставок, однако они искусственно ограничивают конкуренцию банков и МФО. В России микрофинансирование в большей степени, чем в рассмотренных регионах, ориентировано на потребительский сегмент - более $80 \%$ микрозаймов выдается розничным клиентам [3]. Помимо обеспечения финансовой доступности, МФО способствуют стабильности банковской системы за счет того, что обслуживают наиболее рискованных клиентов. Однако часть находится на стыке зон риска, соответствующих бизнес-моделям банков, однако выдача им займов при их уровне риска становится нерентабельной при дей- 
ствующих ограничениях ПСК. Об этом свидетельствует то, что банки используют иные способы увеличения вознаграждения за риск, навязывая клиентам дополнительные услуги: СМС-уведомления, консультативные услуги и юридическую помощь, страхование жизни, в том числе родственников и т.д. В случае отказа заемщика от заключения договора страхования банк вправе не выдавать кредит, так как договор страхования компенсирует часть его рисков. Иные услуги заключаются на формально добровольной основе, однако низкий уровень финансовой грамотности и недобросовестное поведение банков ведут к тому, что практика их навязывания становится весьма распространенной на рынке розничного кредитования - в 2019 году жалобы граждан на подобные нарушения составляли 17,4\% среди обращений, поступивших в Банк России и были на третьем месте по частоте [4]. У клиентов МФО при этом аналогичные проблемы возникали значительно реже: доля жалоб на навязывание дополнительных услуг со стороны МФО составила 2\% в обращениях граждан [4], что объясняется более высокими значениями ПСК - МФО при выдаче займов имеют возможность устанавливать плату за риск, соответствующую риск-профилю заемщиков.

Результатом действующего регулирования потребительского кредитования становится не предполагаемая защита заемщиков от чрезмерно высоких процентных ставок, а принуждение к обращению в МФО либо согласию на менее прозрачные схемы оплаты кредитов с приобретением дополнительных услуг тех заемщиков, которые по своему риск-профилю подходят как банкам, так и МФО.

Отмена предельных значений ПСК могла бы позволить банкам выдавать кредиты более широкому спектру заемщиков. Так как предельные значения ПСК рассчитываются исходя из средних ставок на рынке, процентные ставки даже без учета такого ограничения сдерживаются конкуренцией между кредитными организациями. Вместе с тем, действующий механизм ПСК выполняют менее явную роль по ограничению принимаемых банками рисков при розничном кредитовании населения, поэтому при отмене ограничений ПСК данную функцию могут выполнять надбавки к риск-ко- эффициентам банков, использующимся при расчете капитала, основанные на долговой нагрузке заемщиков, которая напрямую связана с кредитным риском заемщика. Также в отличие от процентных ставок, такие ограничения невозможно обойти за счет дополнительных услуг. Это позволит естественным образом распределить заемщиков исходя из их уровня кредитного риска между МФО и банками. МФО при этом будут ориентироваться исключительно на клиентов, которые банки не готовы обслуживать даже с учетом более высоких процентных ставок, что снизит стоимость заемных средств.

Данные регуляторные изменения не потребуют значительного изменения действующей нормативно-правовой базы. Их реализация возможна на основе показателя долговой нагрузки (далее - ПДН), которой был введен в 2019 году [2]. ПДН представляет собой соотношение доходов и долговой нагрузки заемщика, и при превышении уровня в $50 \%$ увеличивает надбавки к риск-коэффициентам для банков и МФО. Добавление прогрессивной шкалы ПДН позволит количественно ограничить банки при осуществлении высокорискованного кредитования, не исключая саму возможность работать в данном сегменте.

\section{Выво $\triangle \mathrm{b}$}

Так как сближение банков и МФО является общемировой тенденцией, искусственное разделение заемщиков на клиентов банков и МФО через предельные значения ПСК препятствует естественному процессу развития и эволюции МФО как дополняющего элемента системы кредитования, вызывая дисбаланс между спросом и предложением заемных средств. Такое разделение неэффективно, так как стоимость кредита может быть повышена за счет иных дополнительных услуг, что делает процесс кредитования менее прозрачным для заемщика. Отмена данных ограничений и совершенствование действующего механизма ограничения предельной долговой нагрузки заемщиков позволит снизить стоимость заемных средств при сохранении механизма ограничения рисков, принимаемых банковским сектором при потребительском кредитовании.

\section{ЛИТЕРАТУРА}

1. Федеральный закон от 21.12.2013 № 353-Ф3 (ред. от 03.04.2020) «0 потребительском кредите (займе)» // КонсультантПлюс: справочная правовая система. - Версия Проф, сетевая. [Электронный ресурс].— URL: http://www.consultant.ru/document/cons_doc_LAW_155986/ (дата обращения: 05.05.2021)

2. Указание Банка России от 2 апреля 2019 г. № 5115-У «0б установлении экономических нормативов для микрофинансовой компании, привлекающей денежные средства физических лиц, в том числе индивидуальных предпринимателей, и (или) юридических лиц в виде займов, и микрофинансовой компании, осуществляющей выпуск и размещение облигаций» для МФ0 и Указание Банка России от 31.08.2018 № 4892-У «0 видах активов, харак- 
теристиках видов активов, к которым устанавливаются надбавки к коэффициентам риска, и методике применения к указанным видам активов надбавок в целях расчета кредитными организациями нормативов достаточности капитала» для кредитных организаций.

3. Статистические данные к обзору ключевых показателей микрофинансовых институтов Банка России [Электронный pecypc]. - URL: https://www.cbr. ru/microfinance/statistics/ (дата обращения: 04.05.2021)

4. Отчет о работе с обращениями январь-декабрь 2020 года / Официальный сайт Банка России [Электронный ресурc].— URL: https://cbr.ru/Collection/ Collection/File/31975/2020_4.pdf (дата обращения: 04.05.2021)

5. Christen P., Tamara R. Commercialization and mission drift:the transformation of microfinance in Latin America (English). CGAP 0ccasional paper no.5Washington, D.C.: World Bank Group. 2001 [Online] URL: https://documents.worldbank.org/en/publication/documents-reports/documentdetail/122331468265801032/ commercialization-and-mission-drift-the-transformation-of-microfinance-in-latin-america (Date of Access: 04.05.2021)

6. Abrar A., Javaid A.Y. Commercialization and Mission Drift - A Cross Country Evidence on Transformation of Microfinance Industry // International Journal of Trade, Economics and Finance, 2014 vol.5, no.1, pp. 122-125. [0nline] URL: https://www.researchgate.net/publication/271519680_Commercialization_And_ Mission_Drift_In_Micro_Finance_Industry (Date of Access: 04.05.2021)

7. Hage C., G.V. Álvaro. Microfinance in Latin America — The process of Downscaling and Upgrading, 2016. [0nline] URL: https://www.researchgate.net/ publication/303314227_Microfinance_in_Latin_America_-_The_process_of_Downscaling_and_Upgrading (Date of Access: 04.05.2021)

8. International Finance Corporation. Experiences of Microfinance Institutions Serving Very Small to Small Enterprises in Latin America: Based on Case Studies in LAC. Washington, DC. 2014 [Online] URL: https://openknowledge.worldbank.org/handle/10986/21715 (Date of Access: 04.05.2021)

9. World Bank: Microfinance data [Online] URL: https://databank.worldbank.org/source/mix-market (Date of Access: 04.05.2021)

10. Всероссийский банк [Электронный ресурс]. — Режим доступа: https://databank.worldbank.org/source/mix-market. — Дата доступа: 10.05 .2021$.

(с) Высоков Денис Александрович (denisvysokov@mail.ru).

Журнал «Современная наука: актуальные проблемы теории и практики»

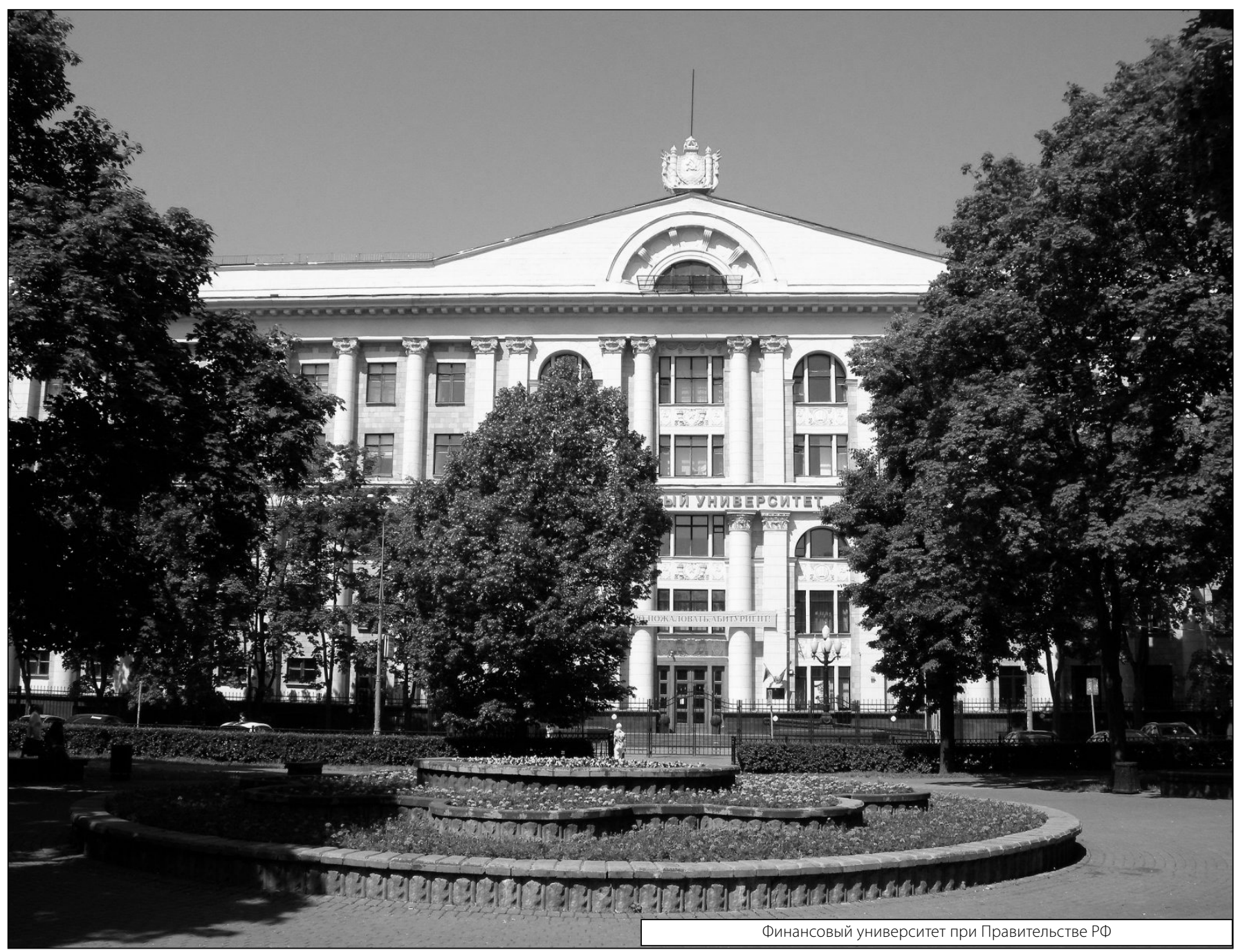

